\title{
Environmental Effects on Thermal Properties of PEl/Glass Fiber Composite Materials
}

\author{
Edson Cocchieri Botelho", José Carlos Bravim Júnior¹, Michelle Leali Costa¹, Maria Candida \\ Magalhaes de Faria ${ }^{1}$
}

\begin{abstract}
The aim of this study was to investigate the effects of hygrothermal exposure, ultraviolet (UV) radiation, salt spray and thermal shock aging on the thermomechanical behavior of glass fiber reinforced by poly (ether-imide) (PEI) composites. Dynamic mechanical (DMA) and Thermomechanical (TMA) analyses have been performed on the aged PEI composites after being submitted to the climatic chambers. Additional techniques have been used to characterize the laminates, such as optical microscopy and infrared spectroscopy [FT-IR] in order to evaluate possible structural changes in these materials. Slight changes were observed both in glass transition temperature and in thermal expansion coefficient as a result from the environmental conditioning used (hygrothermal, salt spray, UV radiation and thermal shock conditioning). Thus, when exposed to these conditions, $\mathrm{PEI}$ /glass fiber laminates maintain its compromise with the performance component.
\end{abstract}

KEYWORDS: Thermoplastic composites, Environmental conditioning, Glass transition temperature, PEI/glass fiber.

\section{INTRODUCTION}

Lightweight composite materials are currently finding extensive use in a wide range of load-bearing engineering applications due to its low density and its high performance in terms of strength and stiffness, besides high cost competitive market. These factors place it in a position to replace the traditional metallic materials already used in the sectors of interest of new technologies such as civil, naval, automotive and aerospace principally (Diaz and Rubio, 2003; Botelho et al., 2003).

With the constant necessity of the development of lightweight structures, the advancements of science and technology in several areas has contributed to the improvement of aviation parts. Structural components of aircraft for civilian and military purposes, such as flaps, rudders, fairings, aileron, fuel tanks, elevator, tail cone and others that were previously made of metal alloys are recently being manufactured in laminated structures of advanced polymeric composites (Kim and Ye, 2005). Currently, several companies are already introducing these parts in their aircraft, among which may be cited as Airbus, Boeing and Embraer (Botelho and Rezende, 2000).

Thermoplastic composite materials have several advantages over traditional thermoset composites in the manufacture of lightweight structures, among them the fact that these materials can be reprocessable, have good costeffectiveness and solidify in a short time compared with slow curing of the thermoset resins, which facilitate their use (Botelho et al., 2003). Between the thermoplastic matrix, the poly (ether-imide) (PEI) is a polymer of high performance 
with good properties, such as strength and stiffness at elevated temperatures, good electrical properties, ample chemical resistance, besides low cost. Furthermore, its glass transition temperature $\mathrm{Tg}$ is high compared to other engineering polymers and can be used in aeronautical applications (Oliveira et al., 2009; Zenasni et al., 2006; Viña et al., 2008; Chevali et al., 2010).

Fiber-reinforced thermoplastic composites in outdoor applications encounter ambient moisture, variation of temperature, salinity and ultraviolet (UV) radiation in addition to stress and temperature, which affects mechanical properties (White and Shyichuk, 2007). These materials are used for long periods of time on airplanes, so it is necessary to know exactly which influence of such factors ensure its safe operation, preserving their properties for the period desired (Yakimets et al., 2004).

When these composite materiais are subjected to distinct and repetitive ranges of temperature, the heating and cooling processes can generate interlaminar stresses, causing defects in the microstructure or delamination of their laminas, and in this cases can occur mechanical deformations of thermal origin (thermal fatigue) (Boualem and Sereir, 2011; Chawla, 2001; Costa et al., 2012; Botelho et al., 2005; Hufenbach et al., 2011; Ramanujam et al., 2008). In this context, a better prediction of the long-term durability of composite materials with organic matrix is essential. In particular, the study of the coupled effects of mechanical cyclic loads, of temperature variations and of a more or less oxidative environment on the damage of these materials remains to be made. When composite laminates with long continuous fibers are subjected to temperature variations, the mismatch of thermal expansion coefficients of fibers and matrix as well as the difference of ply orientation in the lay up are such that local stresses appear, which can take part in the degradation of the laminate. When these thermal variations are cyclic, they induce, at the ply level, cyclic stress variations which can be compared, at this scale, to a fatigue phenomenon. Various types of damage similar to those observed in mechanical fatigue result from these cyclic stresses, like transverse matrix cracking, fiber/matrix debonding and delamination. Few works deal with the long-term behavior of composites subjected to thermal chock condition (Boualem and Sereir, 2011; Chawla, 2001; Costa et al., 2012; Botelho et al., 2005; Hufenbach et al., 2011; Ramanujam et al., 2008).

Concerning moisture influence, this can penetrate into the composite structure by diffusive and/or capillaries processes in accordance with the second Fick's law. It is commonly assumed that water diffuses into the amorphous regions of the polymer where hydrolysis should occur at a rate which depends upon the crystallinity and the initial content of end-groups. In particular, the increase of humidity decreases the mechanical properties of some materials and it is aggravated when combined with high temperatures (Jedidi et al., 2006; Kellogg et al., 2003; Costa et al., 2010; Ray, 2006; Botelho and Rezende, 2010). Moisture absorption may induce severe mechanical and physicochemical changes in polymer matrix or fiber/matrix interphase: polymer chains can undergo a reversible plasticization process, which lowers the glass transition temperature, be subjected to irreversible hydrolysis (Jedidi et al., 2006) and the fiber/matrix interphase can be damaged due to the coupling with internal stresses, for instance. The moisture diffusion process is highly dependent on the temperature and relative humidity (Jedidi et al., 2006; Kellogg et al., 2003; Costa et al., 2010; Ray, 2006; Botelho and Rezende, 2010).

In the case of incidence of UV radiation, it is known that energy is comparable to the covalent bonds in the polymers, thus photo-oxidative reactions may occur and cause degradation in the polymeric matrix, crosslinking among other effects which affects the mechanical resistance of the laminate (White and Shyichuk, 2007; Yakimets et al., 2004).

Also, it is important to understand the behavior of composite materials concerning its exposition in sea water. In the seawater environment, a composite structure is subjected to moisture absorption and fatigue wave loading. Composite materials are known to exhibit some degree of degradation due to moisture absorption. Several studies have examined the mechanical performance of polymeric composites in seawater (Boualem and Sereir, 2011). By comparing cycles to failure as a function of stress amplitude, some concluded seawater exposure gives degradation in performance, while others observed very little degradation (Boualem and Sereir, 2011; Chawla, 2001; Costa et al., 2012; Botelho et al., 2005; Hufenbach et al., 2011; Ramanujam et al., 2008). Few have, however, studied the effect of seawater exposure on thermoplastic composites, which may change, even when there is no significant seawater induced degradation. The effect of moisture on delamination cracking resistance is critical to the durability of composite materials in seawater environment because delamination crack growth has been identified as the most dominant failure mechanism (Boualem and Sereir, 
2011; Chawla, 2001; Costa et al., 2012; Botelho et al., 2005; Hufenbach et al., 2011; Ramanujam et al., 2008).

So, in addition to mechanical properties (tensile, compression, shear etc.), it is important that the maximum service temperature be verified making sure the aircraft flight envelope, based on knowledge of $\mathrm{Tg}$ and melting temperature $(\mathrm{Tm})$.

In this study, moisture, UV radiation, salinity and temperature influences on thermal properties of $\mathrm{PEI} /$ glass fiber laminate have been investigated. The effects of environment on this thermoplastic composite were studied by Dynamical Mechanical Analyses (DMA) and Thermomechanical Analyses (TMA). Additional techniques have been used to characterize the laminates, such as optical microscopy and FT-IR (infrared spectroscopy) in order to evaluate possible structural changes in these materials.

\section{EXPERIMENTAL}

\section{MATERIALS}

The material used in this work is a composite laminated with glass fiber fabric reinforcement and PEI thermoplastic matrix, supplied by the Ten Cate Advanced Composites (Dutch company). Its configuration consists of a laminate with around $2.0 \mathrm{~mm}$ of nominal thickness and woven made in 8 Hardness Satin (HS) configuration.

\section{ENVIRONMENTAL CONDITIONING}

In order to check the mass gain per unit of time on these laminates, the specimens (in triplicate) remained for 60 days at temperature of $80^{\circ} \mathrm{C}$ with a relative humidity of $90 \%$ in climatic chamber. The hygrothermal exposure is based on ASTM D5229/D5229M-04 for composite materials. The samples were dried for 48 hours in a vacuum oven at $60^{\circ} \mathrm{C}$ in order to remove all the moisture present before to be subjected to hygrothermal chamber. The mass control allowed knowing the material moisture absorbing by the Eq. 1 .

$M=\left|\frac{M u-M s}{M s}\right| .100$

Where $M$ is the mass percentage; $M u$, the wet mass and $M s$ is the dry mass.
In the conditioning by thermal shock, it was used a chamber with a hot zone (upper) and a cold zone (lower) interconnected by a vertical lift, which remained for 30 minutes for each step. This chamber was programmed to operate during 1,800 cycles in temperature range from -50 to $+80^{\circ} \mathrm{C}$ in order to simulate the flight envelope of the aircraft (Yakimets et al., 2004; Boualem and Sereir, 2011).

The conditioning methodology by UV exposure was conducted according to ASTM 4329-99 standard. The system used consists of UVB-313 lamps emitting radiation during 8 hours at $60^{\circ} \mathrm{C}$ with an intensity of $0.76 \mathrm{~W} /\left(\mathrm{m}^{2} \mathrm{~nm}\right)$, alternating with 4 hours of water condensation coming from vapor generated at $50^{\circ} \mathrm{C}$. Samples were used in order to set the time intervals of 200, 600 and 1,200 hours. During exposure, the samples were photographed to check the degradation of the material up to 1,200 hours of exposure. In order to evaluate if UV radiation generated a degradation process in $\mathrm{PEI} /$ glass fiber, FT-IR analyses were used in this work. The equipment utilized was a Spectrum One of Perkin-Elmer and the parameters were: analyzed range of 4,000 to $400 \mathrm{~cm}^{-1}$, resolution of $4 \mathrm{~cm}^{-1}$ and gain of 20 scanning. The specimens were analyzed according to the reflective technique (UATR), in which only the surface of the specimen is evaluated.

The coupons submitted to salt spray climatic chamber remained exposed for 15 days, following the ASTM B117-03 standard. The salt solution was prepared with $1 \mathrm{~kg}$ of $\mathrm{NaCl}$ in $19 \mathrm{~L}$ of distilled water, and the final $\mathrm{pH}$ was around 7 . The chamber test temperature was set in $47^{\circ} \mathrm{C}$, the solution, in $35^{\circ} \mathrm{C}$ and the pressure was $1 \mathrm{kgf} / \mathrm{cm}^{2}$.

\section{THERMAL AND MORPHOLOGICAL EVALUATION}

Optical microscopy was used to evaluate the structural quality of the laminates as received and also after the environmental conditionings (hygrothermal, thermal shock and salt spray conditionings), generating information about the quality of the processing. It was used an optical microscope with a Zeiss stereoscopic magnifier.

The ultrasonic inspection was performed by using the pulse-echo method, immersing the specimen in a water bath. The results were provided in A-scan graph, which can detect discontinuities in the composites, e.g. resin-rich regions, voids or cracks. The inspection was carried out with an equipment model MUIS32 from MATEC. The range of probe can be varied from 2.25 to $10 \mathrm{MHz}$. In this research, the $10 \mathrm{MHz}$ probe was more suitable due to the easiest 
assessment to identify the defects. A-scan graph aided to calibrate the patterns of a typical structural composite peaks (reference-without defects) and the difference between the reference peak and the other peaks is referred as attenuation signal. The intensity of the attenuation signals can inform what type of defect might occur. Each point of the laminate creates an A-scan signal, after scanning the entirely laminate. The referred map shows the background echo produced by the A-scan, which can show any flaws along the thickness.

DMA tests were conducted in a bending loading mode, by the DMA equipment, model DMS 6100 from Seiko - SII Nanotechnology on samples with thickness of $2.0 \mathrm{~mm}$, width of $12.0 \mathrm{~mm}$ and length of $50 \mathrm{~mm}$. All measurements were performed with frequency of $1 \mathrm{~Hz}, \mathrm{~N}_{2}$ atmosphere $(20 \mathrm{~mL} / \mathrm{min})$ and heating rate of $3^{\circ} \mathrm{C} / \mathrm{min}$, in the temperature range from 30 to $210^{\circ} \mathrm{C}$. This experiment was used in order to determine the $\mathrm{Tg}$.

TMA was conducted in order to determine $\mathrm{Tg}$ (ASTM E1545) and also thermal expansion coefficient (ASTM E831) for all conditioning studied in the composite PEI/glass fiber. For the TMA tests, it was used $\mathrm{N}_{2}$ atmosphere $(20 \mathrm{~mL} / \mathrm{min})$ and heating rate of $3^{\circ} \mathrm{C} / \mathrm{min}$ in the temperature range from 30 to $210^{\circ} \mathrm{C}$. All TMA tests have been carried out in TMA SS 6100 equipment, EXSTAR6000 model, version 6.2U, from SII Nanotechnology.

\section{RESULTS}

\section{MOISTURE ABSORPTION}

Figure 1 displays the weight gain curves of the PEI/ glass fiber laminates after being submitted to hygrothermal conditioning at $80^{\circ} \mathrm{C}$ and $90 \mathrm{RH}$. The composite weight gain has been normalized according to Eq. 1. The results of three composite specimens are shown in the plot. The reproducibility of the uptake curve is fairly good among different specimens. The uptake curves of the composite obey the Fick's law, with the weight gain initially increasing linearly with respect to (time) $)^{1 / 2}$ and gradually leveling off. Furthermore, the normalized composite weight gain is very close to that of the neat matrix, as can be observed in the literature (Yakimets et al., 2004; Boualem and Sereir, 2011).
According to the results found, the maximum moisture content absorbed by the specimens was $0.18 \%$, determined after around 25 days - showed in Fig. 1 as (hours) $)^{1 / 2}$. Water is only absorbed by the amorphous part of the thermoplastic matrix (Botelho and Rezende, 2010). However, in composite materials reinforced by glass fiber, the surface treatment of the fiber can absorb the moisture, increasing the weight gain promoted by moisture, inside of composite. Therefore, as explained before, in this work, it was not found significant differences between the neat matrix (Botelho and Rezende, 2010) and the results obtained from PEI/glass fiber laminate.

Note that the absorption rate was nearly constant during the first two weeks, about $0.01 \%$ by mass gain. After this period, the composite reaches a state called pseudo-equilibrium with the amount of water maintained practically constant. This behavior is explained by the fact that the free water penetrates the matrix by the concentration gradient with the continuous exposure. After the conditioning period, the amount of moisture in the composite did not vary significantly.

Figure 2 shows representative optical micrographs of the composite submitted to the hygrothermal conditioning (Fig. 2b). The rate of moisture diffusion is controlled by the diffusivity. It is a strong function of temperature and a weak function of relative humidity. Moisture can potentially cause debonding at the fiber/matrix interface not only through chemical attack and reaction, but also through mechanical-chemical effects such as osmotic pressure. The mechanism of attack at the interface is

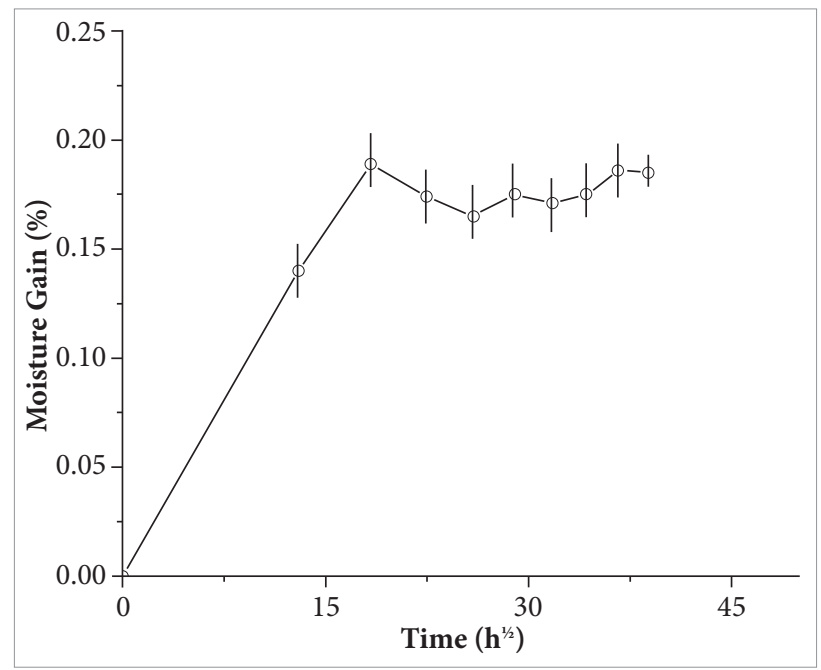

Figure 1. Moisture absorption curve for poly (ether-imide) [PEI]/glass fiber composites. 
decisively governed by the chemistry, structure, morphology, and modes of failure at that interface (Boualem and Sereir, 2011; Chawla, 2001; Costa et al., 2012; Botelho et al., 2005; Hufenbach et al., 2011; Ramanujam et al., 2008).

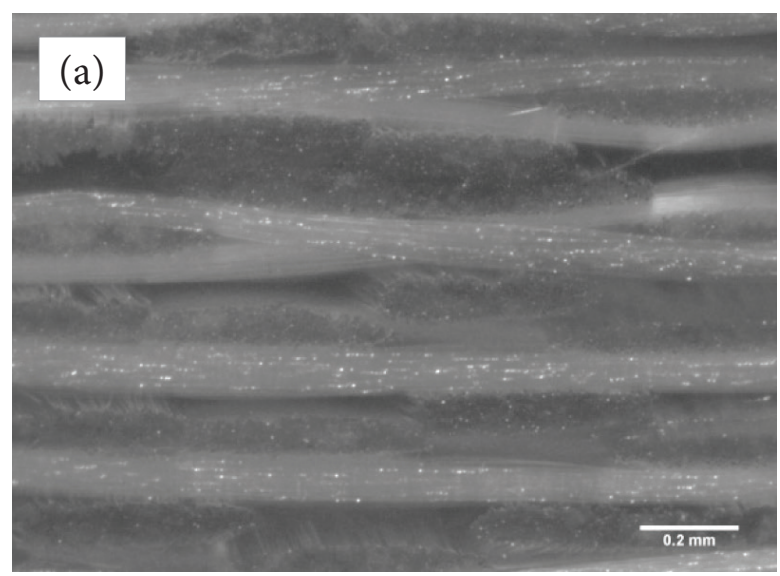

Figure 3 depicted the A-scan ultrasound results for the PEI/glass fiber specimens after being submitted to hygrothermal conditioning. From these results, for specimens subjected to hygrothermal conditioning, there is a small

Figure 2. Microscopy of the composite poly (ether-imide) (PEI)/glass fiber. (a) Unweathered hygrothermal conditioning; (b) after hygrothermal conditioning.

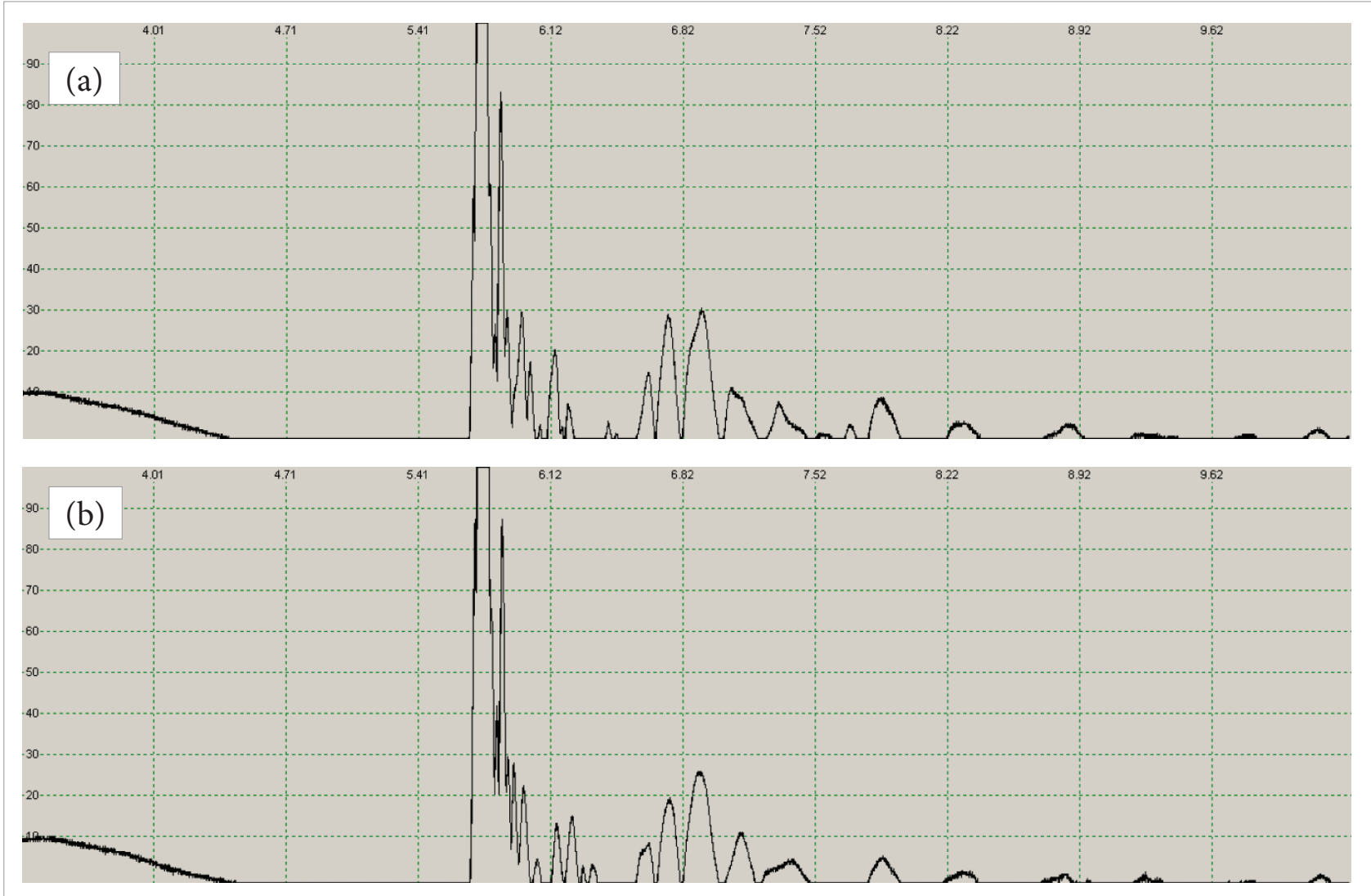

Figure 3. A-scan ultrasound results for poly (ether-imide) (PEI)/glass fibers composites. (a) Unweathered hygrothermal conditioning; (b) after being hygrothermally weathered. 
change of the reference peaks, in which a decrease lower than $10 \%$ in the bottom echo signal can be observed. This small change is not enough to indicate modification in the structure of the laminate, confirming the optical microscopy results.

\section{ULTRAVIOLET DEGRADATION}

Surfaces of all specimens exposed to UV radiation exhibited a distinct change in color from yellow to dark yellow during early stages of the exposure. The discoloration established that photo-oxidation resulted in the formation of chromophoric chemical species, which were absorbed in the visible range of light. Minor changes in surface roughness were also visible for all specimens exposed to UV radiation. Exposure to water vapor condensation did not result in any visible changes in specimen morphology. According to the literature (Botelho and Rezende, 2010), further details regarding the physical processes that govern material degradation can be revealed by examination of the specimens under an optical microscope (OM). Therefore, in this work, no changes in morphology - using $\mathrm{OM}$ - were observed for either the specimen surface or edge, for specimens exposed to UV radiation (Fig. 4). Also, it was observed that the fibers were more exposed after the radiation process. This behavior is expected since it was happen degradation of the matrix during the UV conditioning.

In Fig. 5, the FT-IR spectra for the unconditioned specimens and that one submitted to UV radiation conditioning for different times of exposure are depicted. Analyzing the samples before and after conditioning by UV radiation, small changes can be observed in the chemical structures of the material. In this study, up to 200 hours of exposure, the principal absorption is in the region of $3,300 \mathrm{~cm}^{-1}$, corresponding to stretching $(v)$ hydroxyl group (-OH); beyond the range $3,300-3,600 \mathrm{~cm}^{-1}$, it
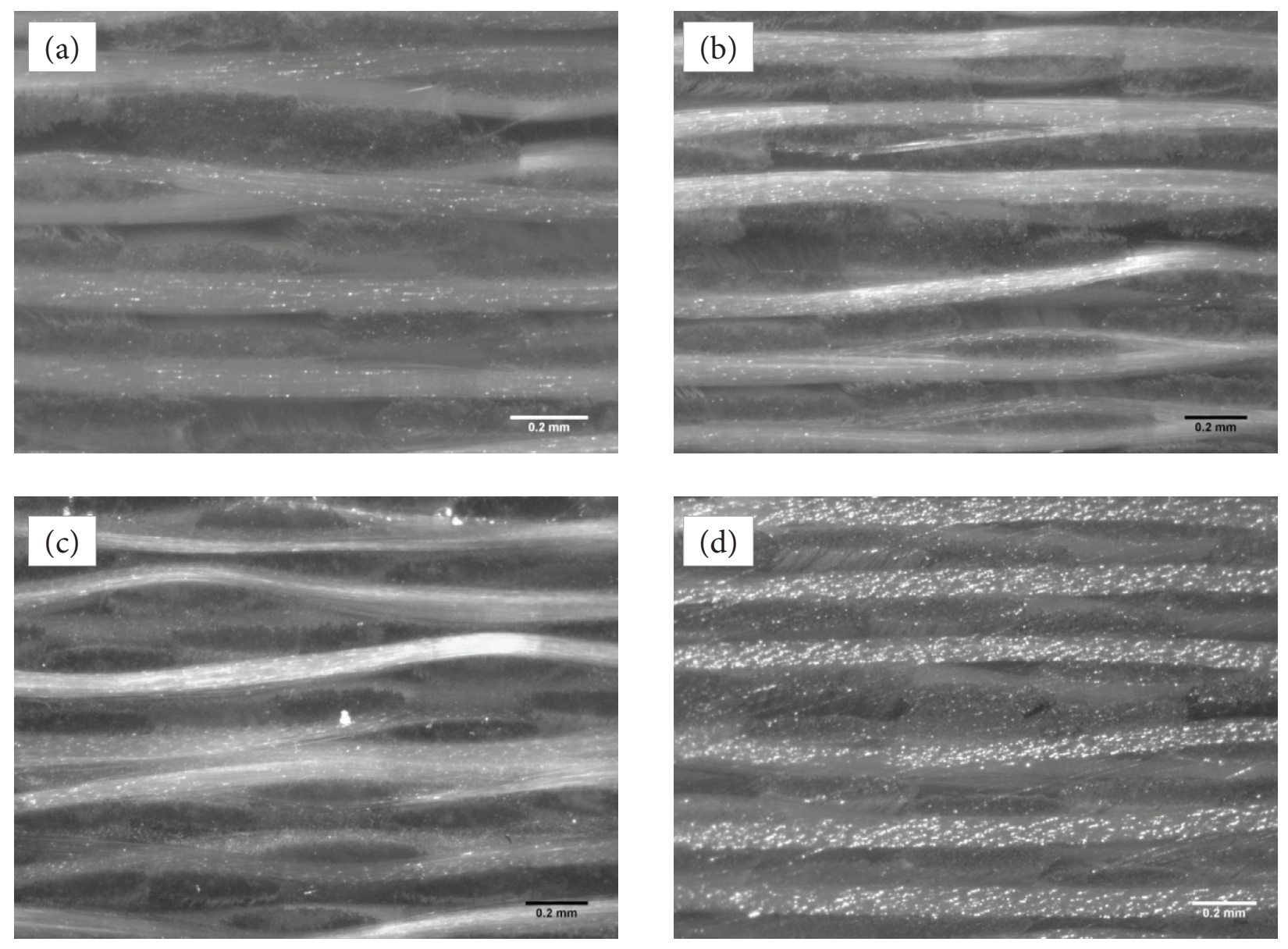

Figure 4. Optical microscopy results for poly (ether-imide) (PEI)/glass fiber composites after being submitted to ultraviolet radiation. (a) 0 hours; (b) 200 hours; (c) 600 hours; (d) 1,200 hours. 
corresponds to the stretching amine $(\mathrm{NH})$. At 600 hours of exposure, it is observed, in addition to the aforementioned events, the band of 2,950 $\mathrm{cm}^{-1}$, which shows a small change, indicating an elongation of aliphatic $\mathrm{CH}$ groups. As for the maximum interval conditioning (1,200 hours), there were small changes, indicating that the compound undergoes degradation (but probably not significant to modify their structural application) in incidence of radiation.

\section{EFFECTS OF THERMAL SHOCK CONDITIONING}

Figure 6 shows the optical micrographs of PEI/glass fiber specimens after being submitted up to 1,000 thermal cycles. Concerning thermal fatigue process, it is expected that the porous generate failures or delaminations process during the thermal cycling. As can be observed in this work, this behavior was not verified by means of $\mathrm{OM}$ for either the specimen surface or edge, after being exposed to thermal cycling condition. This behavior confirms that the cycling number used was not enough to generate thermal fatigue in the composite. In this study, the amount of porosity was not considered, since this behavior depends on the analyzed region of the specimen.

Figure 7 depicts the A-scan ultrasound results for the $\mathrm{PEI} /$ glass fiber specimens after being submitted to thermal cycle conditioning. From these results, significant changes in the peaks were not observed, indicating that probably there are no significant differences in thermal expansion coefficients between the layers.

\section{EFFECTS OF AGING ON THE THERMAL BEHAVIOR: DYNAMICAL MECHANICAL ANALYSES AND THERMOMECHANICAL ANALYSES}

Figures 8 to 10 show the dynamic-mechanical behavior of PEI/glass fiber composite as received and after being
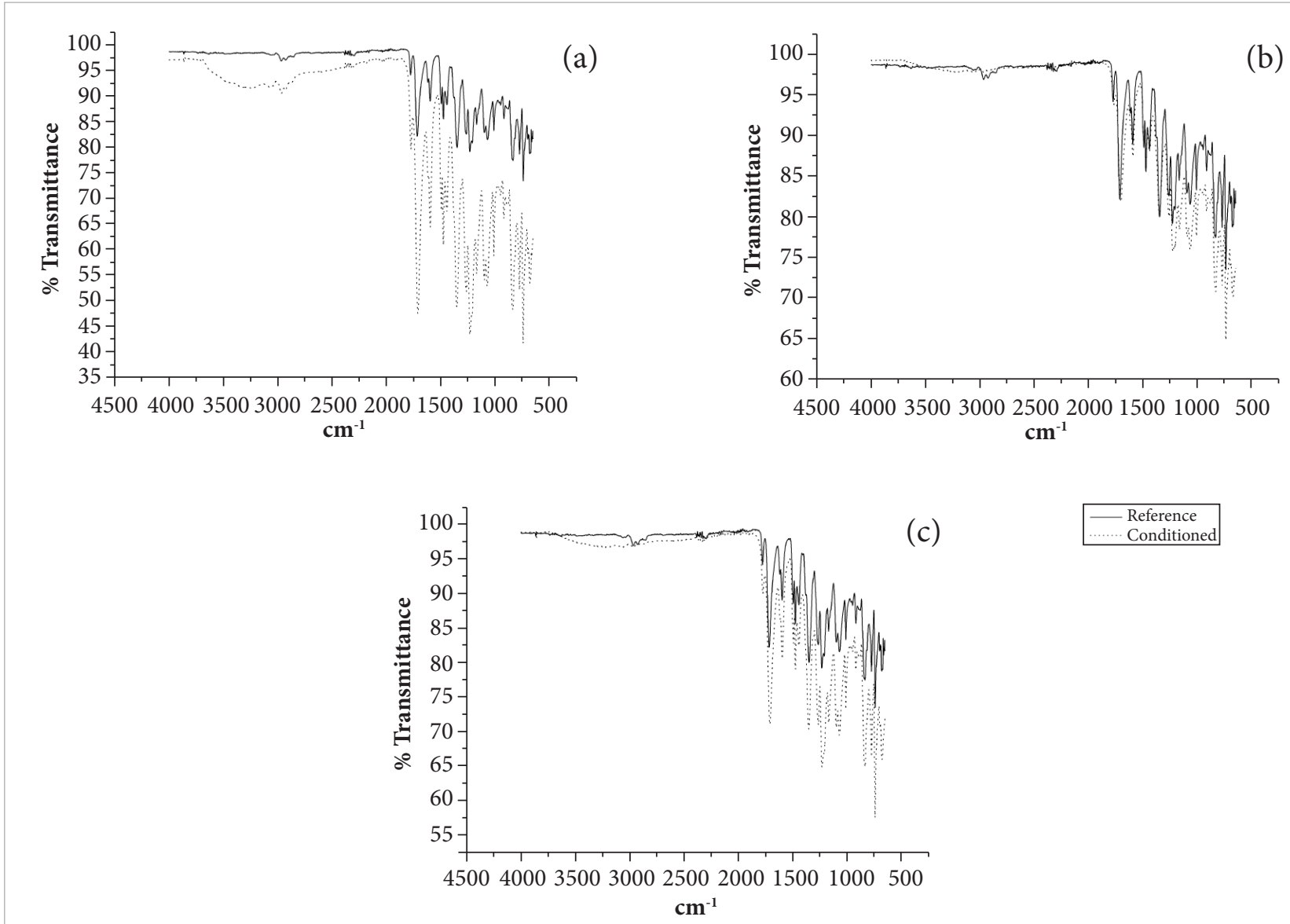

(c)

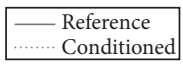

(b)

(a)

$\mathrm{cm}^{-1}$

Figure 5. Infrared spectroscopy (FT-IR) results of the samples subjected to ultraviolet radiation. (a) 200 hours; (b) 600 hours; (c) 1,200 hours. 

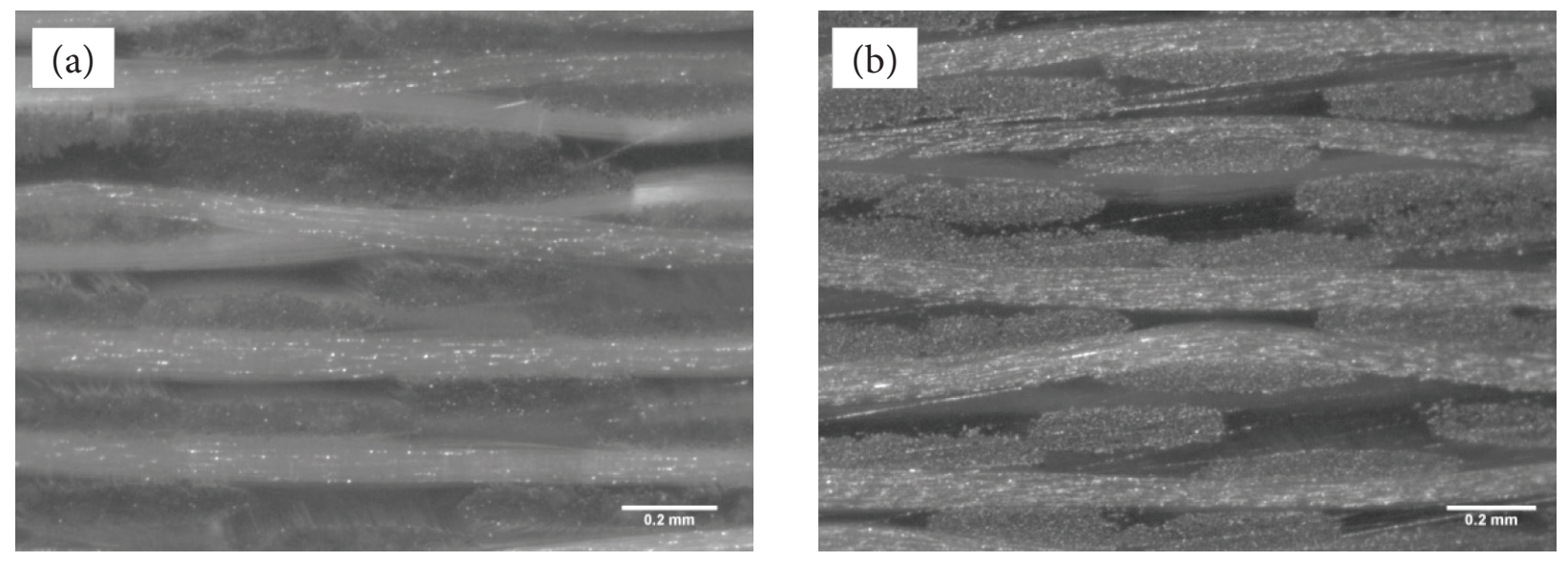

Figure 6. Optical microscopy of poly (ether-imide) (PEI)/glass fiber laminates. (a) Unweathered thermal shock conditioning; (b) after thermal shock conditioning.

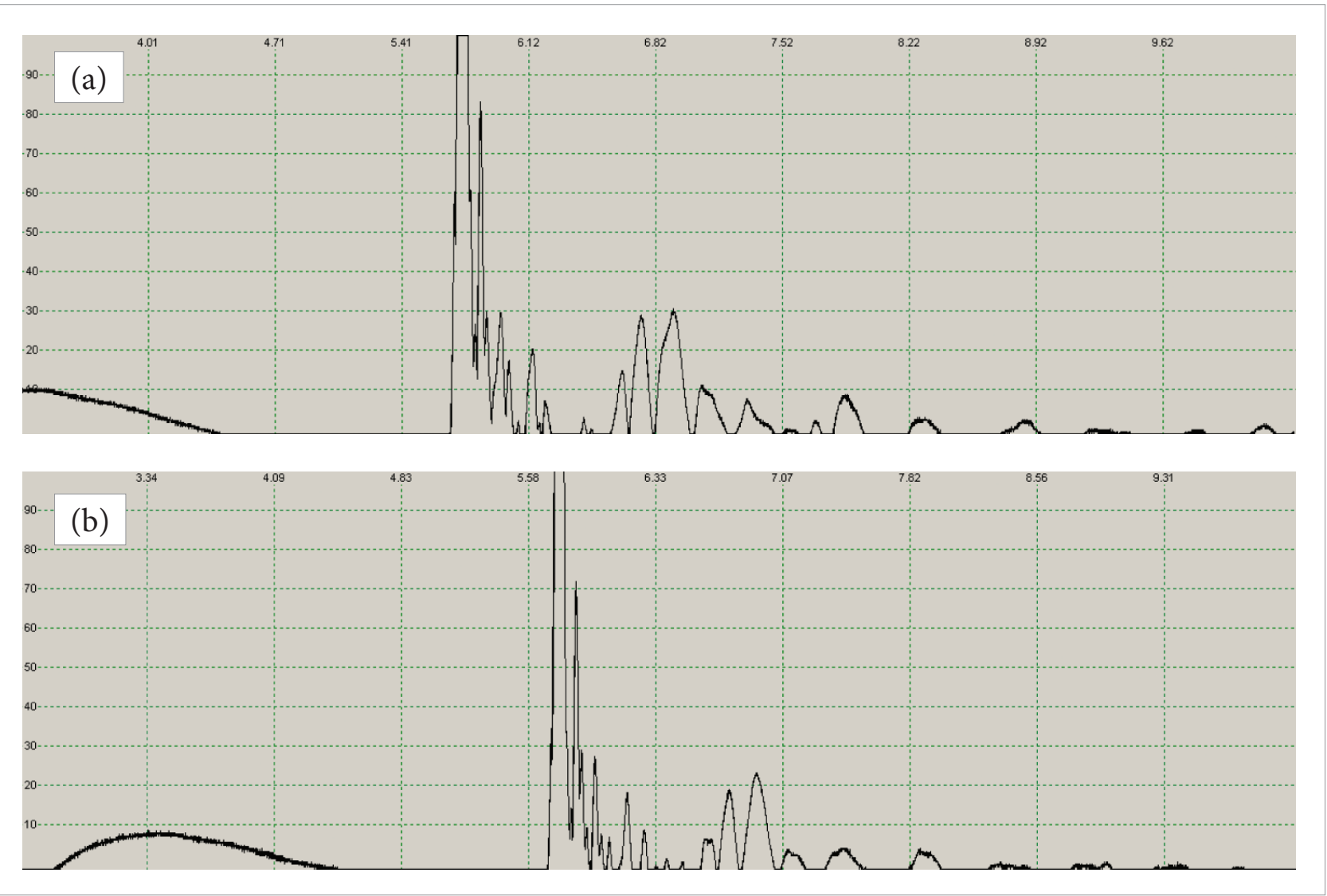

Figure 7. A-scan ultrasound results for poly (ether-imide) (PEI)/glass fibers composites. (a) Unweathered thermal shock conditioning; (b) after thermal shock conditioning. 
submitted to hygrothermal and salt spray conditioning, UV exposition and thermal shock, respectively. Figures 11 to 13 present the TMA curves for all conditioning studied in this work

The method of determining the $T g$ in the DMA can be a manner for disagreement, as at least five ways are in current use. Depending on the industry standards or background of the operator, the peak or onset of the tan delta curve, the onset of the E' drop, or onset or peak of the E" curve may be used. The values obtained from these methods can differ up to $25^{\circ} \mathrm{C}$ from one another on the same run. In addition, a $10-20^{\circ} \mathrm{C}$ difference from Differencial Scaning Cromatography (DSC) or TMA is also seen in many materials. Differences as great as $25^{\circ} \mathrm{C}$ have been reported. In practice, it is important to specify exactly how the $\mathrm{Tg}$ should be determined (Menard, 2008). According to Table 1 , the Tg values obtained by DMA (peak of $\tan \mathrm{d}$ ) are lower than the values of $\mathrm{Tg}$ measured by TMA, in the order of $20^{\circ} \mathrm{C}$.
As can be observed in Fig. 8 and also in Table 1, the hygrothermally aged glass fiber reinforced specimen did not show significant decrease in the magnitude of the relaxation peak ( $\mathrm{gg})$, since the samples subjected to hygrothermal conditioning had a reduction of only $3.7 \%$ compared to the unweathered sample values; and this decrease for sample subjected to saline conditioning was only $2.7 \%$ ( $T$ g obtained from onset E' drop values). Similar behaviors were observed when $T g$ was obtained from E" and $\tan \delta$. The phenomenon of decrease in the $\mathrm{Tg}$ temperature for the hygrothermally aged glass fiber reinforced sample is related to plasticization, which induces an increase in the amorphous chain mobility but, since for PEI/glass fiber composite the absorbed moisture content was very low, this effect was not so pronounced.

In the characteristic plot of the storage modulus (Fig. 8a), hygrothermally and salt spray aged glass fiber reinforced samples had a lower storage modulus compared to unweathered specimen, but it was observed only around
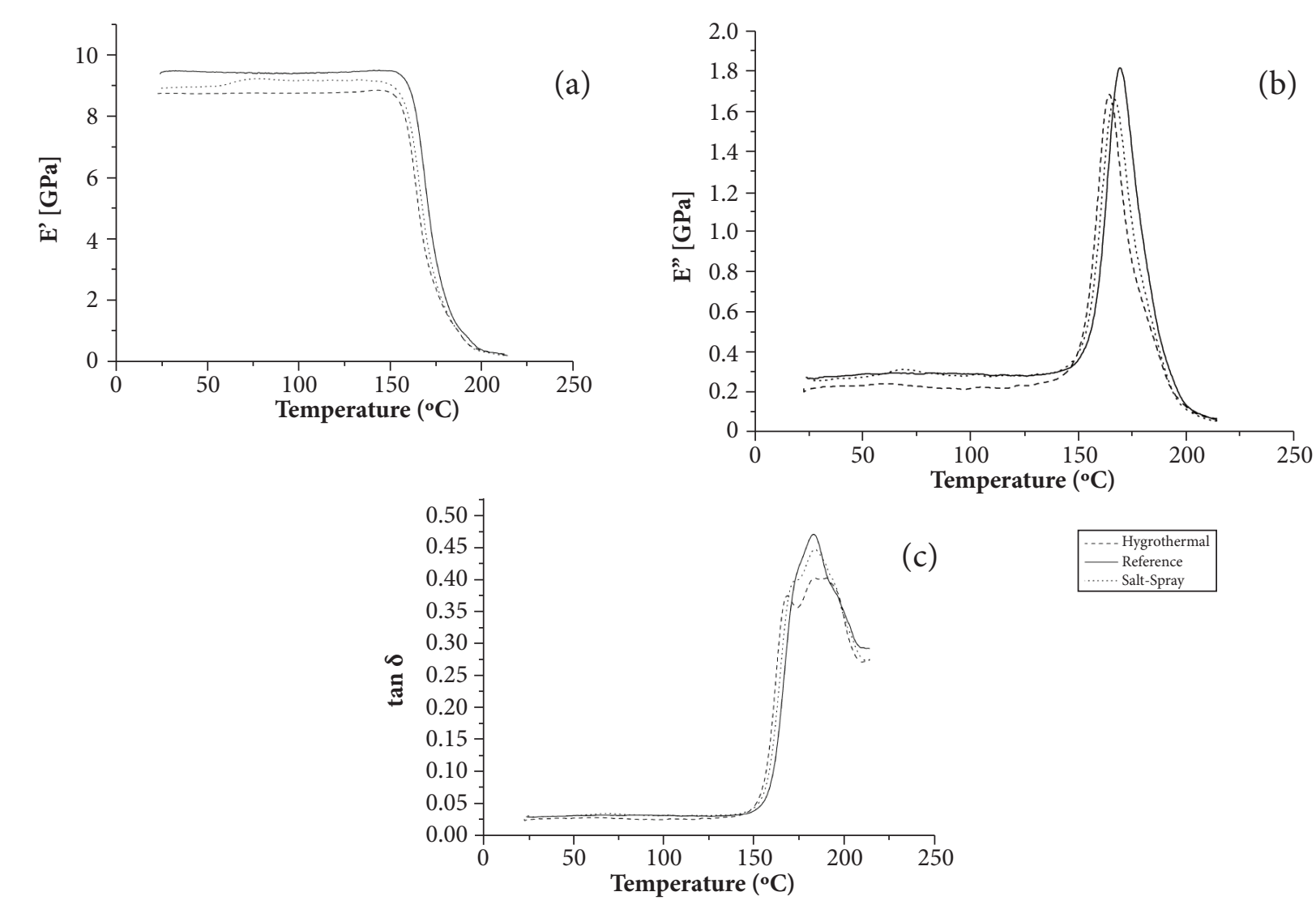

Figure 8. Dynamic mechanical analysis (DMA) curves of the poly (ether-imide) (PEI)/glass fibers composite after being conditioned in salt spray and hygrothermal chamber. (a) E'; (b) E"; (c) tan $\delta$. 
$5 \%$ of decrease of this property. This behavior is probably related to the plasticizing effect promoted by the moisture absorption. Also, it was observed a second peak in Fig. 8c, probably related to the beginning of plasticizing effect.

Figure 9 and Table 1 show the results of DMA for the samples submitted to the UV exposure. As can be seen, the $\mathrm{Tg}$ value increases as the time of exposure to the UV radiation increases. As can be observed from this result, the $\mathrm{Tg}$ value obtained from the onset of E' was $164^{\circ} \mathrm{C}$ for the unweathered specimen. After being submitted to UV radiation during 200, 600 and 1,200 hours, the PEI/glass fiber laminate increases the $T g$ values in $1.89,2.31$ (table shows the contrary) and $4.98 \%$, respectively. This increase in $\mathrm{Tg}$ after exposure to UV condensation indicates that the PEI matrix underwent

Table 1. Dynamic mechanical analysis (DMA) and Thermomechanical analysis (TMA) results obtained from aged poly (ether-imide) (PEI)/glass fiber laminate.

\begin{tabular}{|c|c|c|c|c|}
\hline Conditioning & Tg (onset E' drop - DMA] $\left({ }^{\circ} \mathrm{C}\right.$ ] & $\operatorname{Tg}$ (peak of $\tan \delta-\mathrm{DMA}]\left(^{\circ} \mathrm{C}\right.$ ) & $\operatorname{Tg}(\mathrm{TMA})\left({ }^{\circ} \mathrm{C}\right)$ & $\alpha \times 10^{-6}\left[{ }^{\circ} \mathrm{C}^{-1}\right]$ \\
\hline Reference & $164 \pm 0.8$ & $184 \pm 0.8$ & $204 \pm 2.3$ & $16 \pm 0.5$ \\
\hline Hygrothermal & $167 \pm 0.7$ & $186 \pm 1.7$ & $206 \pm 1.2$ & $19 \pm 1.5$ \\
\hline Salt spray & $164 \pm 0.3$ & $183 \pm 0.2$ & $202 \pm 0.5$ & $37 \pm 0.5$ \\
\hline UV - 200 hours & $169 \pm 0.8$ & $185 \pm 0.9$ & $204 \pm 1.4$ & $38 \pm 3.6$ \\
\hline UV - 600 hours & $167 \pm 0.8$ & $185 \pm 0.6$ & $206 \pm 0.4$ & $35 \pm 1.3$ \\
\hline UV - 1200 hours & $173 \pm 0.5$ & $186 \pm 0.4$ & $216 \pm 0.5$ & $27 \pm 3.8$ \\
\hline Thermal shock & $170 \pm 0.3$ & $183 \pm 0.2$ & $183 \pm 0.5$ & $26 \pm 3.0$ \\
\hline
\end{tabular}

Tg: glass transition temperature.
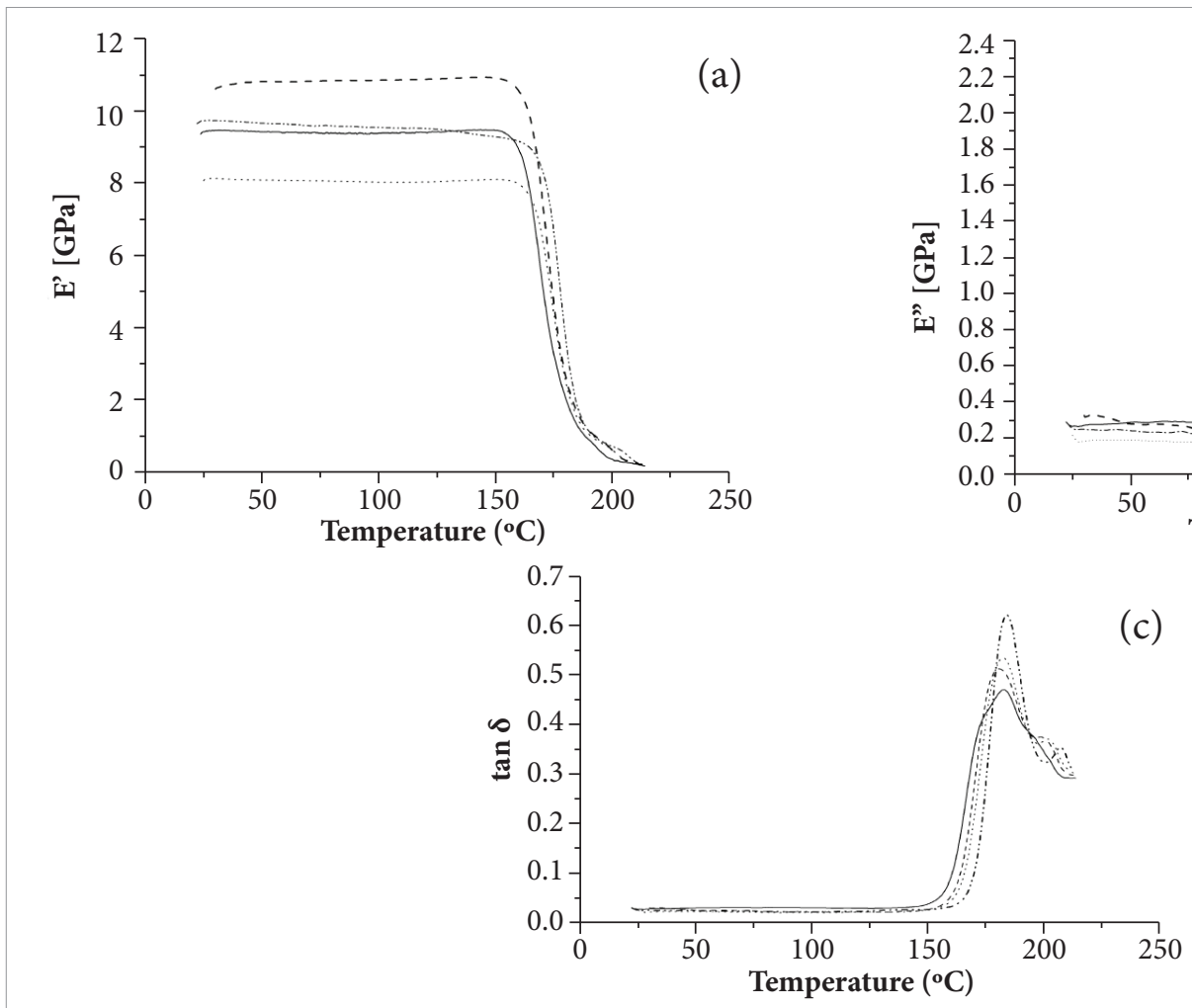

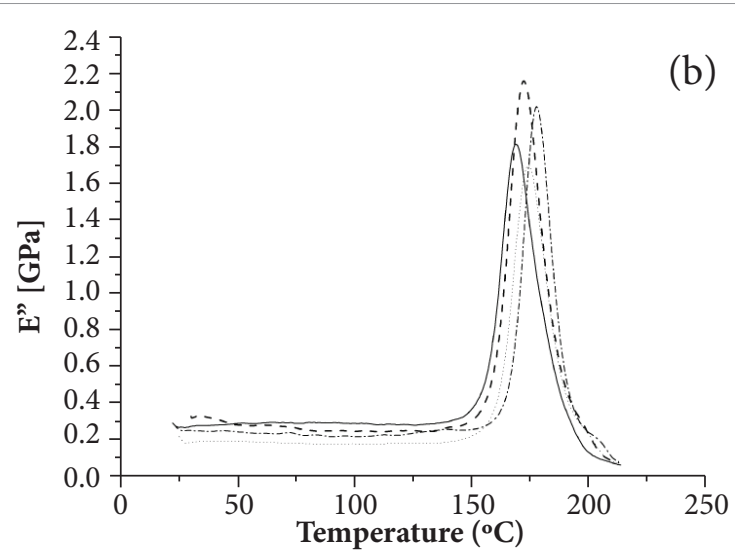

c)

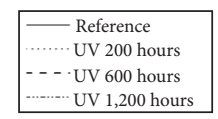

Figure 9. Dynamic mechanical analysis (DMA) curves of the poly (ether-imide) (PEI)/glass fiber composite after being submitted to ultraviolet (UV) radiation. (a) E'; (b) E"; (c) tan $\delta$. 
hydrolysis and irreversible crosslink process, but very slightly, confirming the FT-IR results. However, since this process was significant only for specimens submitted to UV radiation after 1,200 hours, higher periods are necessary to confirm this result.

The measurement of $\mathrm{Tg}$, among other reasons, presents scatter because the glass transition is actually defined as a temperature range within large range molecular motion is activated by the temperature increase. The problem is more complex in the case of wet polymer samples with high $\mathrm{Tg}$ values, because the samples lose moisture to a significant extent in the glass transition region, where the molecular mobility and the moisture diffusion are enhanced. Thus, probably there is a gradient of moisture concentration through the samples in the $\mathrm{Tg}$ region, and a corresponding distribution of temperature dependent of the molecular relaxation times (Costa et al., 2005).
The moisture level leads to different changes in $\mathrm{Tg}$ depending on the particular characteristics of molecular structures and matrix/fiber interface interactions of the matrix system. The different behavior of the samples studied (samples submitted to the hygrothermal conditioning and samples submitted to the UV radiation and humidity) and changes in the distribution of relaxation times associated with the $\alpha$-transition ( $T g$ ) could not have been caused only by the plasticization effect, because the both specimens were submitted to the humidity conditioning before the DMA tests. When $\mathrm{Tg}$ variations and FT-IR results are compared, initial breaks of chains apparently occur, with a maximum of reticulation in 600 hours, and some breaks of chains happen in 1200 hours, when the E' results are evaluated.

Figure 10 and Table 1 present the DMA results obtained for PEI/glass fiber composite after being exposed to thermal

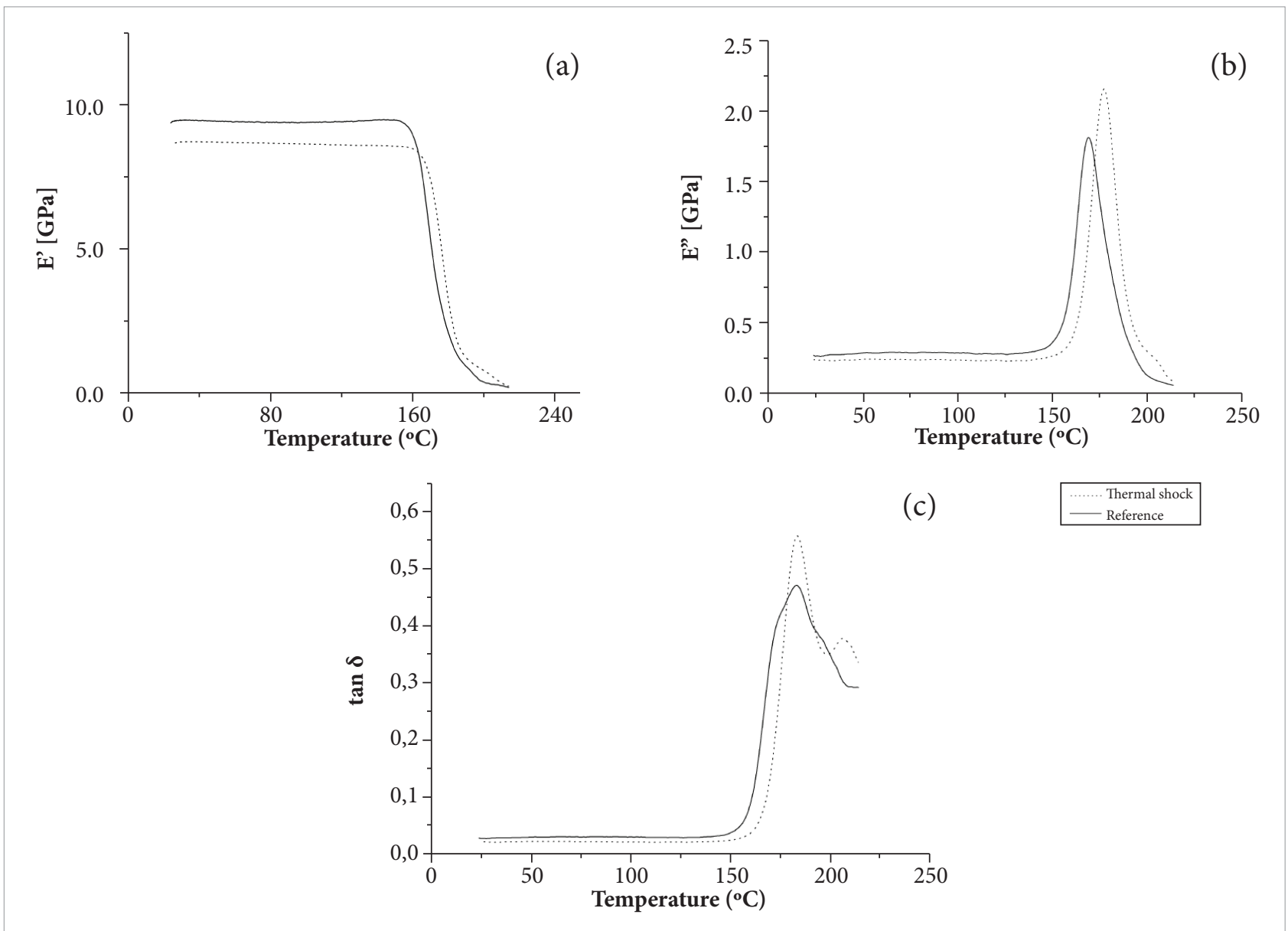

Figure 10. Dynamic mechanical analysis (DMA) curves of the poly (ether-imide) (PEI)/glass fiber composite after being submitted to thermal shock conditioning. (a) E'; (b) E"; (c) tan $\delta$. 
shock chamber during 1,000 cycles. In this case, it is observed that the $\mathrm{Tg}$ value, as determined by onset of $\mathrm{E}$, increases slightly in only $3.54 \%$ in the sample after being submitted to thermal cycling $\left(170^{\circ} \mathrm{C}\right)$, due probably to the reticulation process of the matrix. Since there is no evidence that this conditioning generates thermal fatigue, as showed from OM experiments, these results were expected.

Figures 11 to 13 and Table 1 present the results obtained from TMA experiments. As can be observed, the Tg tendency values were similar to those found by using DMA experiments with exception of thermal shock sample.

Also from TMA experiments, it was observed that the values of thermal expansion coefficient change as a function of the kind of conditioning to which the sample was submitted. The polymeric matrices used in composite present positive and high thermal expansion coefficient (typically higher than the steel alloy and aluminum). However, because of their polar groups, these matrices may both absorb moisture and expand, or release moisture and shrink. These expansions and contractions dimensional per unit length are called hygroscopic deformation, and in many cases are directly proportional to the amount of water that the matrix absorbs or releases. Thus, it can be seen that all $\alpha$ values obtained after the conditioning increased, indicating that the system PEI/fiberglass expanded by moisture absorption.

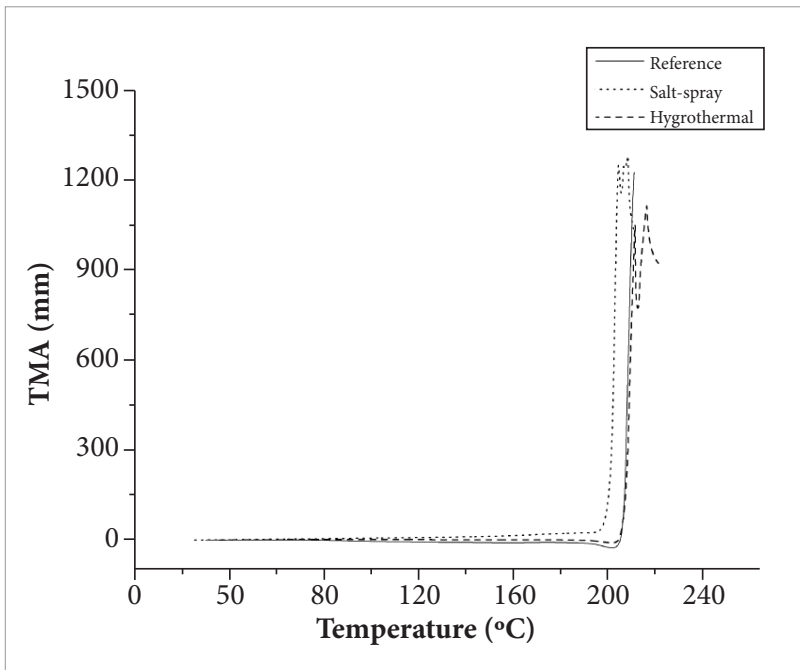

Figure 11. Thermomechanical analysis (TMA) curves of the poly (ether-imide) (PEI)/glass fiber composite for saline and hygrothermal conditionings and reference state.

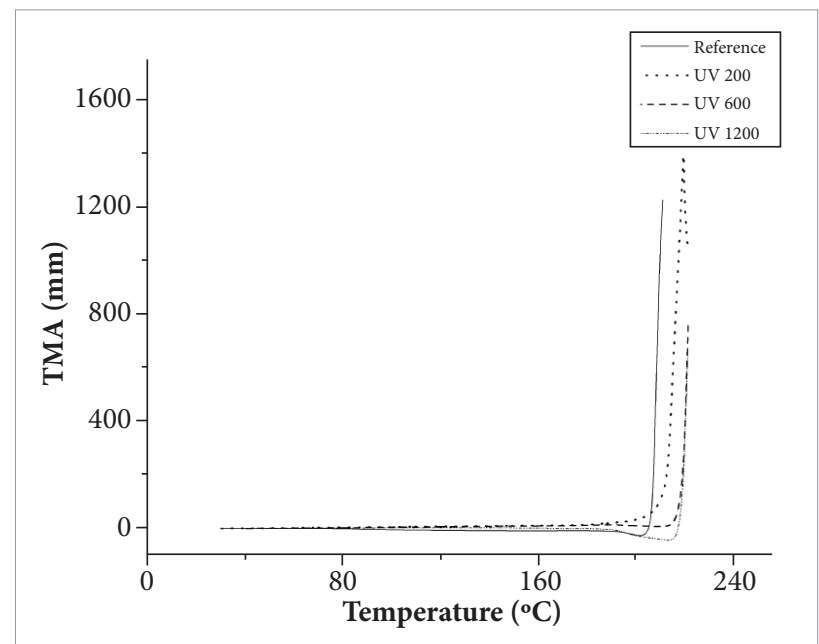

Figure 12. Thermomechanical analysis (TMA) curves of the poly (ether-imide) (PEI)/glass fiber composite for conditioning in ultraviolet radiation and reference state.

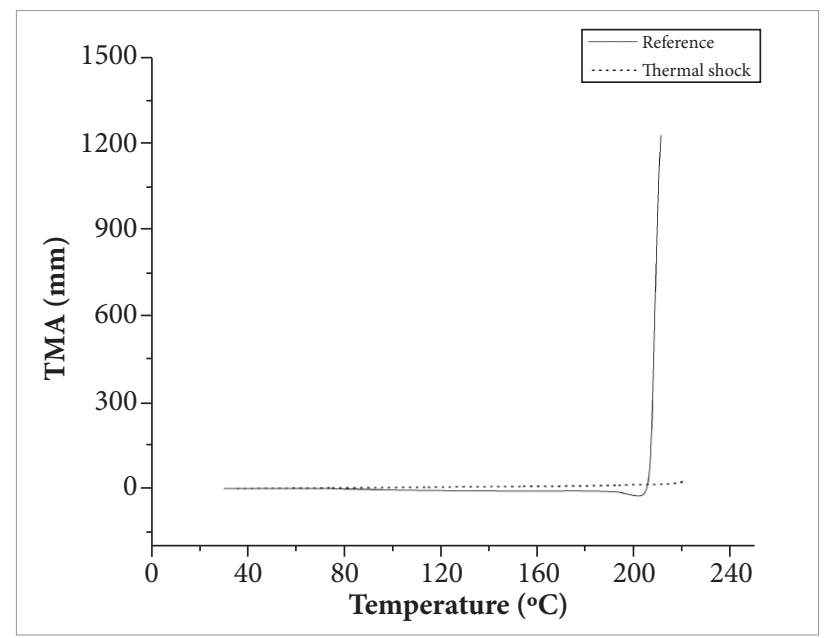

Figure 13. Thermomechanical analysis (TMA) curves of the poly (ether-imide) (PEI)/glass fiber composite for shock thermal conditioning and reference state.

\section{CONCLUSION}

From the results of this research work, it was found that the material absorbed about $0.18 \%$ of moisture, which is considered low when compared to other composites used in aeronautical applications found in the literature, and the absorption rate was constant during the first two weeks of hygrothermal exposure. The hygrothermal conditioning does not show significant evidence that the plasticizing effects 
resulted in decrease of properties of PEI/glass fiber laminates. Similar observation can be attributed to the salt spray conditioning effects on thermal properties of PEI/glass fiber, since $\mathrm{Tg}$ was not significantly affected by this conditioning.

The specimens submitted to UV radiation presented small changes in the chemical structures of the material, indicating that the compound undergoes degradation, but this behavior was not so appreciable to indicate decreases of thermal properties. The increase of $T g$ after UV condensation exposure during 1,200 hours indicates an irreversible crosslink process, but very slight.

The thermal shock conditioning promotes slight increase in the $\mathrm{Tg}$ value, but the cycling number used was not enough to generate thermal fatigue in the composite. According to this work, it was not observed significant differences before and after shock conditioned specimens on thermal properties to disqualify this composite when applied in aeronautical field, when changes of the temperature are evaluated.

\section{ACKNOWLEDGMENTS}

The authors acknowledge the financial support received from FAPESP and are also grateful to Ten Cate Company for supplying the material.

\section{REFERENCES}

Botelho, E.C. et al., 2005, "Processing and Hygrothermal Effects on Viscoelastic Behavior of Glass Fiber/Epoxy Composites", Journal of Materials Science, Vol. 40, No 14, pp. 3615-3623.

Botelho, E.C. et al., 2003, "Mechanical Behavior of Carbon Fiber Reinforced Polyamide Composites", Composites Science and Technology, Vol. 63, No 13, pp. 1843-1855.

Botelho, E.C. and Rezende, M.C., 2010, "Evaluation by Free Vibration Method of Moisture Absorption Effects in Polyamide/Carbon Fiber Laminates", Journal of Thermoplastic Composite Materials, Vol. 23, No 2, pp. 207-225.

Botelho, E.C. and Rezende, M.C., 2000, "O uso de Compósitos Estruturais na Indústria Aeroespacial", Polimeros, Vol. 10, № 2, pp. e4-e10.

Boualem, N. and Sereir, Z., 2011, "Accelerated aging of unidirectional hybrid composites under the long-term elevated temperature and moisture concentration", Theoretical and Applied Fracture Mechanics, Vol. 55, No 1, pp. 68-75.

Chawla, N.E.A, 2001, "Thermal-shock behavior of a Nicalon-fiberreinforced hybrid glass-ceramic composite". Composites Science and Technology, Vol. 61, No 13, pp. 1923-1930.

Chevali, V.S. et al., 2010, "Effect of environmental weathering on flexural creep behavior of long fiber-reinforced thermoplastic composites", Polymer Degradation and Stability, Vol. 95, pp. 2628-2640.

Costa, A.A. et al., 2012, "The effect of thermal cycles on the mechanical properties of fiber-metal laminates", Materials \& Design, Vol. 42, pp. 434-440.

Costa, A.P. et al., 2010, "Influence of environmental conditioning on the shear behavior of poly (phenylene sulfide)/glass fiber composites", Journal of Applied Polymer Science, Vol. 118, No 1, pp. 180-187.

Costa, M.L. et al., 2005, "Hygrothermal Effects on Dynamic Mechanical Analysis and Fracture Behavior of Polymeric Composites", Materials Research, Vol. 8, No 3, pp. 335-340.
Diaz, J. and Rubio, L., 2003, "Developments to manufacture structural aeronautical parts in carbon fibre reinforced thermoplastic materials", Journal of Materials Processing Technology, Vol. 143-144, pp. 342-346.

Hufenbach, W. et al., 2011, "The effect of temperature on mechanical properties and failure behaviour of hybrid yarn textilereinforced thermoplastics", Materials \& Design, Vol. 32, No 8-9, pp. 4278-4288.

Jedidi, J. et al., 2006, "Accelerated hygrothermal cyclical tests for carbon/epoxy laminates". Composites Part A: Applied Science and Manufacturing, Vol. 37, No 4, pp. 636-645.

Kellogg, K.G. et al., 2003, "Influence of moisture and reducedtemperature thermal cycles on the izod notch toughness of a pultruded glass-fiber composite", International Journal of Offshore and Polar Engineering, Vol. 13, No. 3, pp. 232-239.

Kim, K.Y. and Ye, L., 2005, "Influence of Matrix and Interface on Transverse Mechanical Properties of CF-PEI Thermoplastic Composites at Elevated Temperatures", Journal of Reinforced Plastics \& Composites, Vol. 24, No 4, pp. 429-445.

Menard, K.P., 2008, "Dynamic Mechanical Analysis: a practical introduction", CRC Press, Taylor \& Francis Group, USA, 218p.

Oliveira, G.H. et al., 2009, "Influência da Temperatura no Desempenho Mecânico de Compósitos PEl/Fibras de Vidro", Polímeros: Ciência e Tecnologia, Vol. 19, No 4, pp. 305-312.

Ramanujam, N. et al., 2008, "Interlaminar fatigue growth of crossply composites under thermal cycles", Composite Structure, Vol. 85, pp.175-187.

Ray, B.C., 2006, "Temperature effect during humid ageing on interfaces of glass and carbon fibers reinforced epoxy composites", Journal of Colloid and Interface Science, Vol. 298, No 1, pp.111-117. 
Viña, J. et al., 2008, "Wear Behavior of a Glass Fiber-Reinforced PEI Composite", Journal of Thermoplastic Composite Materials, Vol. 21, No 3, pp. 279-286.

White, J.R. and Shyichuk, A.V., 2007, "Effect of stabilizer on scission and crosslinking rate changes during photo-oxidation of polypropylene", Polymer Degradation and Stability, Vol. 92, No 11, pp. 2095-2101.
Yakimets, I. et al., 2004, "Effect of photo-oxidation cracks on behaviour of thick polypropylene samples", Polymer Degradation and Stability, Vol. 86, No 1, pp. 59-67.

Zenasni, R. et al., 2006, "Effect of Hygrothermomechanical Aging on the Interlaminar Fracture Behavior of Woven Fabric Fiber/PEI Composite Materials", Journal of Thermoplastic Composite Materials, Vol. 19, No 4, pp. 385-398. 